\title{
Estado y actores sociales en la política pública. El caso del Pro.Cre.Ar en la provincia de Entre Ríos (2012-2015)
}

The State and social actors in public policies. The case of Pro. Cre. Ar in the Entre Ríos Province

\author{
Graciela Mingo \\ Magister en Metodología de la \\ Investigación, Licenciada en Ciencia \\ Política, cursando el Doctorado en \\ Ciencias Sociales. Docente Investigadora \\ en la Facultad de Trabajo Social, UNER. \\ Directora de la especialización en \\ Metodología de la Investigación, \\ FCEco, UNER \\ gmbevilac@gmail.com
}

\section{Elisa Sarrot}

Magister en Metodología de la Investigación, Licenciada en Ciencias de la Educación. Docente Investigadora Facultad de Trabajo Social UNER.

Coordinadora académica de la

Especialización en Metodología de la investigación. FCEco UNER. elisarrot@yahoo.com.ar
Fecha de recepción:

18.8.17

Fecha de aceptación:

21.6.18

\section{Resumen}

El artículo analiza al plan Pro.Cre.Ar como política pública activa para llegar a la vivienda propia por parte de los sectores medios de la sociedad. Se describen los objetivos y principios que sostuvieron la propuesta en el período 2012/2015, las miradas de distintos actores relacionados: adjudicatarios, trabajadores que participaron en la construcción de las viviendas, y otros actores favorecidos por la diversidad de piezas interactuantes en la concreción de las mismas. Se reconocen las reconfiguraciones del nuevo dispositivo urbano que el plan propicia, anclados en espacios rururbanos de localidades pequeñas. Se indaga el sentido de esta política pública, como una de las tantas formas activas en que el Estado interviene ante las demandas de la ciudadanía.

Palabras clave: política pública de vivienda - Pro.Cre. Ar - actores de la política pública - espacios rururbanos.

\section{Abstract}

This article focuses on the Pro. Cre. Ar plan as a public policy to reach access to the ownership of homes by middle 
class families. The goals and principles that underpinned the plan's proposal in 2012/2015 are described, as well the views of the many actors involved: contractors, workers employed in building the houses, together with other actors involves in the diversity of interacting pieces in the implementation of Pro. Cre. Ar. Reconfigurations of urban spaces that the plan provokes are acknowledged, contributing to the appearance of rur-urban spaces. It also dips in the direction of this public policy, as one of the many ways in which the State intervenes with regard of citizens' demands.

Key words: housing policies - Pro. Cre.Ar - social actors in public policies - rururban areas.

\section{Introducción}

En este artículo se analiza el Plan Pro.Cre.Ar (Programa de Crédito Argentino del Bicentenario para la Vivienda Única Familar) que adquirió particular relevancia en nuestra investigación sobre el sector de la construcción, por su incidencia tanto a nivel urbano como rururbano, ${ }^{1}$ así como en la posibilidad de acceder a un bien -la vivienda propia- fundamentalmente por parte de los sectores medios de la población en el aglomerado Gran Paraná de la provincia de Entre Ríos.

El análisis del Plan está centrado en distintas miradas: sus destinatarios, los trabajadores que participaron en la construcción a partir del mismo, y otros actores favorecidos por la diversidad de elementos que interactúan en la producción de una vivienda.También exploramos en el sentido de esta política pública, como una de formas activas en que el Estado interviene en la asignación de recursos, en este caso, a través de un régimen de protección pública que otorga acceso a un sector de la ciudadanía en la obtención de la vivienda propia.

A pesar de la distancia formal entre Estado y ciudadanos, propia de una política pública y en este caso una política social, observamos en el Pro.Cre.Ar que la gestión política fue respondiendo a las vicisitudes de su concreción. Así, de acuerdo a Offe (1994) analizamos a la misma como una acción política en la que el Estado, a través de un mecanismo de integración y cohesión, intenta proteger relaciones sociales necesarias, como fuerza simbólica concretizada en la búsqueda de mayor inclusión social. 


\section{Cuestiones metodológicas}

En primera instancia analizamos los contenidos, objetivos y metas del Pro.Cre.Ar, para lo cual recurrimos con sentido crítico a la lectura de las fuentes documentales disponibles en las páginas web de la ANSES (Administración Nacional de la Seguridad Social), como también a información periodística extraída de medios de comunicación escritos. La perspectiva en el análisis fue escudriñar en el sentido subyacente a la política social de la vivienda única, paso primordial en el conocimiento de los objetivos del plan y en la interpretación de un estilo de intervención que el Estado nacional introdujo entre los años 2012 y 2015 . Se describe para ello el devenir y los alcances que esta política fue adquiriendo en ese periodo. Estas fuentes se complementan con las observaciones y registros de los investigadores cuando se recorrían las zonas rururbanas, a las que se llegaba a través de la cartografia correspondiente, para apreciar determinadas trazas urbanas en imágenes consideradas como indicadores epistémicos de lo que ha implicado este plan para los sectores medios de la sociedad. Como expresa Jimenez Rosano (2005), trabajar con los planos y la fotografia permitió detectar las huellas que imprimen en el mapa social local las construcciones realizadas, la ubicación en que se encuentran y la peculiaridad de dotar de estructura urbana al lugar seleccionado. Así, en la tarea de análisis e interpretación, se integra la lectura del diseño del plan, sus modelos de viviendas, y las imágenes tomadas, enmarcadas en la cultura visual que describe el lugar en el que se crean y discuten significados. ${ }^{2}$

En el desarrollo de la investigación en terreno se buscó la aproximación a los actores involucrados en el Plan a través de entrevistas semi estructuradas, dirigidas a lograr un proceso de empatía que, como plantean Denzin y Lincoln (2002) produce un intercambio no neutral -de hacer preguntas y recibir respuestas- sino que representa un esfuerzo colaborativo. Los intercambios develaron el contexto de los adjudicatarios, tanto en los discursos obtenidos como en las oportunidades de recorrida de espacios en que se ejecutaban las construcciones. Así las narrativas estuvieron referidas al contexto y desde un proceso holístico se trató de avanzar en de manera sinérgica entablando contacto con otras voces diversas: los trabajadores y los profesionales del rubro de la construcción. El período de análisis abarca desde la implementación del plan en el año 2012 hasta el último sorteo realizado a principios de 2015.

\section{El déficit habitacional en Argentina}

No es nuevo en la Argentina el tema de las dificultades de algunos grupos sociales para acceder a la vivienda. Los sectores sociales de ingresos bajos están imposibilitados de llegar por vías formales a suelos urbanizados y los sectores medios no acceden a la vivienda propia por dificultades para obtener crédito, sumadas a los fuertes desequilibrios del desarrollo económico a nivel regional. De acuerdo al Censo Nacional de Población y Vivienda de 2010 el déficit habitacional llegaba a 3,5 millones de viviendas, incluyendo 
a quienes alquilaban o vivían en vivienda deficitaria (INDEC). Esta información se basa en proyecciones efectuadas por organismos privados que estiman la necesidad de alcanzar un incremento anual de 36.000 viviendas por año para saldar ese déficit (FEDI, 2015).

Entre otros antecedentes están los reclamos de los distintos sectores sociales, los acontecimientos en el Parque Indoamericano (2010) y los datos del déficit habitacional, que en su conjunto pusieron de relieve una de las tantas asignaturas pendientes de satisfacer, pues algunos proyectos anunciados por el gobierno anteriormente estaban referidos a la construcción de vivienda a través de créditos y no se concretaron, o tuvieron un éxito mínimo, como fue en el año 2008/09. ${ }^{3}$ En ese entonces, se buscaba paliar los posibles efectos de la crisis financiera internacional del 2008 con epicentro en EEUU, ${ }^{4}$ y con ese fin entre las políticas anti-cíclicas se anunció la construcción o remodelación de propiedades a través de los bancos con una tasa media; pero esta medida fue anunciada y luego se vio postergada, razón por la cual quienes accedieron en ese momento a créditos, debido a las altas exigencias bancarias, fueron únicamente jóvenes profesionales que tenían un salario bastante elevado (Mingo y otros, 2013).

Cuando los sectores medios vivencian la imposibilidad de acceder a una vivienda propia, se produce un drenaje de ingresos disponibles a solventar un alquiler. De allí que el Pro.Cre.Ar surgió como una alternativa para satisfacer la demanda y dar una respuesta a la adquisición de la vivienda única.

\section{Ideas rectoras del Pro.Cre.Ar.}

Presentamos algunos puntos neurálgicos del Pro.Cre.Ar. como uno de los últimos programas para adquirir la vivienda propia propuestos por el gobierno nacional de la presidenta Cristina F. de Kirchner (su gestión finaliza en diciembre de 2015), acorde a uno -entre muchos- de los reclamos de la ciudadanía.

Para su implementación se creó el Fondo Fiduciario Público, ${ }^{5}$ modo de financiamiento que requirió la participación de la ANSES, el Ministerio de Economía y Finanzas Públicas, e inversores privados interesados en la línea de los desarrollos urbanos. El Banco Hipotecario fue elegido para la ejecución del plan, haciéndose cargo de la implementación en el otorgamiento de los créditos, y luego se encargó de los cobros de cuotas de los créditos asignados a los adjudicatarios, garantizando de esta manera su ejecución y “constituyéndose legalmente en el fiduciario del Fondo.” (ANSES, 2012).

La esencia del programa fue atender, mediante líneas de crédito, la problemática habitacional en todo el territorio de nuestro país, según diferentes demandas y de acuerdo a las realidades socioeconómicas de cada región y a las diferentes situaciones de quienes se inscribían en el mismo. Entre las líneas estaban la construcción, la ampliación, 
terminación y refacción de viviendas, y la adquisición de aquellas construidas por el Plan a través de desarrollos urbanísticos. El plan no solo apuntó a la vivienda propia, sino que en sus argumentos incluye la promoción de otros ejes muy significativos de un estado presente: impulsar la actividad económica a través del incentivo a la construcción de viviendas y su efecto dinamizador, ser partícipe en el desarrollo activo de la inversión pública y en el subsidio al consumo masivo, y apuntalar la generación de empleo en todo el país mediante la incorporación de mano de obra directa e indirecta.

La línea de créditos del Plan ofreció plazos para su devolución en cuotas durante 20 a 30 años (Anses, 2012). Los montos otorgados ascendieron hasta $\$ 500.000$, y la relación cuota-ingreso podía llegar al 40\%. Las tasas oscilaron del 2 al 14\%. Las edades requeridas en los solicitantes abarcan entre 18 y 65 años. La adjudicación de los créditos se realizó mediante sorteos por lotería nacional. Por último, cada línea de crédito fue diseñada para que sea accesible y pueda saldarse en su totalidad. Un aspecto sobresaliente que se fue dando con el avance del plan fue la habilitación de una línea destinada a aquellas familias que no tenían terreno pero deseaban acceder a una vivienda de los desarrollos urbanísticos del plan. Se buscó con ello inscribir personas o familias que residan en las localidades próximas al lugar donde se construían los mismos. Esto significó la creación de zonas urbanísticas en tierras fiscales otorgadas por los gobiernos nacional, provincial o municipal, según se pactara en cada región.

\section{El Pro.Cre.Ar en cifras}

El programa comenzó a funcionar a mediados del mes de junio de 2012, y en el período analizado (hasta febrero de 2015) se realizaron 11 sorteos con 7 repechajes (última instancia para aquellos que no salieran sorteados). En 2012 se inscribieron 21.863 familias, y se otorgaron 11.604 créditos (ANSES, sorteo). Estas cifras no se detuvieron, sino que, por el contrario, fueron creciendo año a año.

En total se otorgaron 400 mil créditos en 4 años, 200 mil en el período 2012-2014 para construcción, ampliación, terminación y refacción de viviendas. Del total, casi el 85\% pertenece a una de las líneas de crédito destinada a viviendas únicas, con un total de 171.143 casas terminadas, refaccionadas y/o ampliadas. El 25\% restante fueron otorgados dentro de la línea denominada "desarrollo urbanístico"; traducido en números, 29.325 casas en los 79 desarrollos urbanísticos que se habilitaron en todo el país. El plan tuvo una vigencia de tres años con las características que se fueron mencionando, y en la totalidad de sorteos y repechajes se inscribieron 1.35 millones de familias, de las cuales fueron sorteadas 567.280 (ANSES). 
Las líneas directas y desarrollos urbanísticos, a la manera de una radiografia del Pro.Cre.Ar en las distintas regiones del país, fueron identificadas por zonas:

Zona Centro: 61.232 viviendas.

Noroeste Argentino: 19.119 viviendas.

Noreste Argentino: 10.542 viviendas.

Cuyo: 18.156 viviendas.

Patagonia: 18.114 viviendas.

Provincia de Bs. As. / Ciudad Autonoma:

73.305 viviendas.

En todo el país participaron 649.261 familias y se otorgaron créditos en las diferentes líneas a 309.606 familias.

Una de las zonas más favorecidas en la adjudicación de créditos fue la Región Centro (Córdoba, Santa Fe y Entre Ríos), detrás de Provincia de Bs. As y Ciudad Autónoma. Del 100\% de los créditos, la Zona Centro representó el 30,54\%, con un agregado: que en la capital de Entre Ríos se levantó uno de los 79 desarrollos urbanísticos, en los terrenos que pertenecían al Ejército Nacional Argentino, que incorporó para su ejecución a más de 600 obreros. ${ }^{6}$

En la provincia de Entre Ríos donde ancla este estudio, se otorgaron más de 8.200 préstamos hipotecarios, en los 11 sorteos realizados incluidos los repechajes. La inversión, contabilizada en función de la cantidad de créditos que se otorgaron en el marco del plan, fue de 87.225 millones de pesos (ANSES) al año 2015. En uno de los documentos descriptivos del plan se hacía mención a dar respuestas a las necesidades de la población, lo cual permite desde una lectura más profunda conjeturar que se responde con dicho crédito hipotecario a las dificultades para acceder a la vivienda propia, vivenciadas y expresadas por sectores medios en Argentina.

\section{El Pro.Cre.Ar y la retórica de la política pública}

Entendemos que este plan es coherente con la retórica específica de la política pública y específicamente como una política social asumida por el gobierno y, junto a otras propuestas adoptadas, puso de relieve acciones que marcaron significativos puntos de ruptura con los patrones de funcionamiento tradicionales. Los objetivos anteriormente reseñados muestran que la implementación de esta política estuvo guiada por la accesibilidad a la vivienda propia -agregamos para el sector medio de la sociedad argentina- y el afán de dar continuidad al empleo y dinamizar el mercado a través del consumo de bienes y servicios. Esto parece indicar que la propuesta política considera las evidencias del contexto social y económico: caída de la producción y por ende del crecimiento económico (2011) -que pasó a ser negativo después de haber crecido a un ritmo del 
8\% entre los años 2003/07-. Fue a partir de la declaración de la crisis internacional de 2008 que comienza a notarse la retracción del crecimiento económico a un 4\% entre 2007 y 2011, y el estancamiento se expresó a fines del 2011 con un 2\% después de las elecciones realizadas en octubre de este último año en las que el Frente para la Victoria obtuvo un nuevo triunfo (Tiempo de Economía, 2015).

En algunas de sus pautas, requisitos y formas de implementación, el Pro.Cre.Ar se vincula con Pro.Creauto (2014) que trató de evitar el derrumbe de la producción automotriz, aunque su impacto fue menor pues no logró retener ni revertir la caída de patentamiento de vehículos de uso doméstico en dicho momento. Tanto en uno como en otro, por el modo de adquisición (de la vivienda o del auto respectivamente) y por la modalidad de financiamiento, se evidencia un Estado promotor de políticas anticíclicas, activando mecanismos motorizadores de la economía, a través del consumo, como una manera de frenar la caída del empleo que se había comenzado a apreciar.

Es posible descubrir además otro sentido implícito en la apuesta de estas políticas: la utilidad dada a los fondos recuperados por la re-estatización del sistema previsional que puso fin al sistema de las AFJP, a través de una ley sancionada por el Congreso en diciembre de 2008. De allí que la acción social emprendida por el gobierno ha implicado un posicionamiento dirigido a responder a las cuestiones sociales apremiantes, como intento de equiparar en algunos niveles la desigualdad y la fragmentación social.

A contrapelo de lo sucedido en la década de 1990, momento en que primó un posicionamiento -propio del neoliberalismo- de corte privatista, de descentralización y focalización del gasto social en poblaciones específicas (Soldano, 2009), la gestión del Frente para la Victoria implementó políticas extensivas de restitución de derechos a partir de políticas públicas que intervienen con un sentido "universalizador", permanentes y complementarias de las políticas de promoción del empleo y del consumo de la población.

En este sentido el Pro.Cre.Ar intentó dar respuesta a las necesidades de vivienda fundamentalmente de los sectores medios, y al mismo tiempo, respondió a ciertas reglas del mercado inmobiliario, incorporando nuevas líneas para acceder al crédito -refacciones, ampliaciones, etc.- y agregando, en los primeros meses de 2015, los planes en 12 cuotas a través de las tarjetas de crédito para adquirir insumos de la construcción (altamente afectados por la inflación) y otros bienes. Tampoco escapó a este plan la cuestión del acceso a la tierra, pues se les dio intervención a los Estados provinciales y/o municipales en negociaciones por los loteos de terrenos que ampliaron las posibilidades otorgadas por esta política, acorde a cada región geográfica y las normativas reguladoras que del manejo de las tierras fiscales, en cada territorio. Producto de estas negociaciones se llegó a acuerdos importantes y, ante las tensiones presentadas por los adjudicatarios, tomaron protagonismo las jurisdicciones municipales. 
Es por ello que se entiende que esta acción política responde a la promesa de cumplir con la justicia social (D’Amico, 2013), pues se constata una valoración de necesidades leídas en el correlato social, cuando se trata de reactivar la economía y reconocer un colectivo social por su demanda. Este posicionamiento político tiene presente la cuestión social al contribuir a la mejora en la calidad de vida de una parte de la ciudadanía, como una de las directrices posibles, y apuntalando por ende acciones en pos de sociedades más incluyentes, morigerando a su vez las profundas brechas en la distribución del ingreso.

El Pro.Cre.Ar en su diseño aspiraba a garantizar un piso de mayor homogeneidad material (Soldano y Andremacci; 2006) mejorando las condiciones de vida de una de las franjas sociales -sector medio- demandantes de vivienda. Afirmamos entonces que constituye una política direccionada a sectores medios de la sociedad argentina, quienes han experimentado dificultades en el acceso a la vivienda propia desde hace más de treinta años a esta parte. En este punto es importante reflexionar que quienes integran este amplio sector social ya no muestran homogeneidad en sus pautas culturales y fortaleza en los lazos sociales como otrora, sino que, como consecuencia de transformaciones estructurales globales que en el país tuvieron expresión en las políticas neoliberales de los años noventa (siglo XX), las necesidades y demandas se expresan de diferentes maneras en este sector, lo cual lo vuelve a veces altamente fragmentado.

Al examinar en la lógica subyacente a la política pública con alto contenido social y activa, palpamos que primó la idea de alcanzar la protección pública del entramado social, pues el acceso a la vivienda propia suaviza la profundización de las desigualdades y la fragmentación en los modos de sociabilidad (Castel, 1997) y a su vez promueve la reactivación del consumo. Está en la superficie la idea de inclusión social, pues la forma de pensar y ejecutar se sustenta en aportar a la constitución de sociedades menos fragmentadas, desde una visión amplia de inclusión que tiene presente el mercado laboral.

En los propios documentos del Pro.Cre.Ar se mencionaba la creación de oportunidades, concepto que se reforzaba en otros programas del Ministerio de Desarrollo Social y lo planteaban como uno de los ejes de las políticas sociales, dándoles valor a "los ciudadanos como sujetos titulares de derechos, (...) permitiendo implementar diversas políticas orientadas a mejorar las condiciones de vida de los sectores más vulnerables de la sociedad."

De acuerdo a D’Amico (2013) en las decisiones de la agenda pública se abogaron desde la faz axiológica valores sustentados en los principios republicanos y liberales, en los que sobresalen los intereses de una clase sobre el resto, diferentes a lo acontecido en la última etapa del Siglo XX. En los '90 la población había sido interpelada en torno a una lista de "atributos" con los que se calificaba a quienes vivían "en y con problemas sociales" (Soldano, 2009). Dichos atributos eran indicadores de pobreza o vulnerabilidad (Cardarelli - Rosenfeld, 2001). Entonces, identificada esta población mediante 
mediciones estadísticas, se focalizaba a quién debía estar dirigida la política social, y recién entonces surgía el destinatario de la misma. En el Pro.Cre.Ar estos procedimientos no aparecen, aunque en su concreción e implementación se van visibilizando "restricciones" que debían sortear los destinatarios, dadas por "diferencias" - ser o no trabajador registrado, tener o no capacidad de pagar la cuota, etc.-.

Los documentos, la presentación realizada en el anuncio del PROCREAR y luego la puesta en marcha, estaban articulados a la manera en que el gobierno concebía la presencia y por dicho motivo la intervención del Estado, y a la forma de diseñar y concretar la política social, bajo el principio de acercarse a la "inclusión social" a través de la promesa de achicar las brechas producidas por las asimetrías sociales. Lo mismo puede decirse de la denominada Asignación Universal por Hijo (AUH), cuyas acciones marcaron una postura diferenciadora en el principal mecanismo articulador de la política social, distinguiéndose de los principios del Estado mínimo en la Argentina en materia de políticas sociales, precisamente con el neoliberalismo en que se apuntaba, como dijimos, a una distribución focalizada.

En definitiva, en esta oportunidad se direccionó la agenda pública a través del fortalecimiento del rol del Estado como garante de la cohesión social y se garantizó el financiamiento con un Fondo Fiduciario Público, en que estuvieron presentes recursos de la ANSES.

\section{El vínculo en la regulación del mercado de trabajo}

El plan se vinculó a otros propósitos, como el de no menguar el movimiento de la economía y fomentar el consumo interno, lo cual es valioso en un momento en el cual el crecimiento económico había entrado en una meseta. Además contribuyó a regular la fuerza de trabajo, como mecanismo instrumental que garantizó fuentes de ingresos dentro del mercado laboral (Cortés y Marshall, 1993). El énfasis en propiciar una política pública extendida que diera respuesta a varias demandas de la ciudadanía, en la que el trabajo -en lugar del ingreso- ocupa una categoría central, asegura la protección social, cuya premisa radica en que no hay trayectoria que genere más empoderamiento para salir de la vulnerabilidad social que la de incorporarse al mercado de trabajo, lo cual también aporta a menguar las brechas en la distribución del ingreso en la sociedad (Alonso y Di Costa, 2013).

Los vínculos con el mercado de trabajo fueron evidenciados en los testimonios de los obreros, a quienes entrevistamos con el propósito de que en sus narrativas puedan explicar la modalidad de trabajo lograda. En la heterogeneidad de los trabajadores entrevistados, algunos pertenecían a empresas constructoras y en esos casos la participación en la construcción de viviendas Pro.Cre.Ar fue como un segundo empleo a contra-turno, los fines de semana o en los períodos entre que finaliza una obra y comienza otra, fenómeno conocido en los estudios del sector como intermitencia laboral. "Es así... trabajamos algunos meses hasta que nos reincorporen en la empresa constructora”. 
$\mathrm{Al}$ aproximarnos a estas situaciones asomó un contrasentido. El plan buscaba mantener o incentivar el empleo, menguar el conflicto social y por ende proteger el volumen de la mano de obra. Pero es evidente que en algunas construcciones se dieron acuerdos laborales precarios, como también en las refacciones y ampliaciones donde las relaciones contractuales fueron verbales entre adjudicatario y albañil, o con cuentapropistas, lo cual denota reglas propias de la informalidad, al igual que ocurre en el contexto general de este oficio.

Los adjudicatarios de los créditos consensuaron diferentes acciones respecto al marco de tratamiento y protección cuando trabajaban en la obra personas que no eran familiares, aunque en el trabajo "familiar" fue situación frecuente, ya que no se dispusieron dentro del crédito partidas para cubrir los gastos de mano de obra. El tema requirió de atención para evitar posibles inconvenientes futuros, y en algunos casos se gestionó la cobertura de seguro que cubriera riesgos de accidentes de trabajo en obra. Esta información fue corroborada luego por los representantes de UOCRA sede Paraná.

No obstante estas paradojas, los testimonios evidenciaron que esta política abrió nuevas alternativas laborales, y el sector de la construcción tuvo mayores posibilidades en general, y en particular los jóvenes que, aún sin haber finalizado los estudios secundarios, pudieron incorporarse a trabajar dentro de la obra como peones, tarea para la cual no se exige calificación alguna, sino "un cuerpo joven y fuerte" (Mingo et al. 2013). Esto es un beneficio parcial, en un contexto de meseta en el campo laboral que disciplina al trabajador, lo coloca en condiciones asimétricas y reproduce la inseguridad laboral, situación inherente a las propias reglas del capitalismo (Cortés y Marshall, 1992).

Incide en estas situaciones que la contratación para la realización de las obras se efectúa de manera particular e informal, entre quien obtuvo el Pro.Cre.AR y el propio trabajador, pues no es frecuente la contratación de una empresa constructora de envergadura. Los escasos -y fijos- montos otorgados en el crédito no alcanzan para cubrir los costos de una empresa, sumado a las otras restricciones propias de la obra a las que se vieron sometido gran parte de los destinatarios.

A diferencia de estos casos, en las líneas de crédito para "desarrollos urbanísticos" del Programa, destinadas a la edificación de un barrio, sí participan necesariamente por licitación las empresas constructoras. En ese marco, las contrataciones se realizan respetando el sistema de seguridad social y forman parte del trabajo registrado o formal, lo cual se debe a la amplitud y dimensión que adquiere la obra de dichos complejos habitacionales. No obstante que el trabajo formal sea la excepción en las construcciones Pro.Cre.Ar, se encuentra igualmente una división del trabajo en las obras, pues algunos cumplen la función de ayudante albañil, y otros son jefes o capataces de la obra. 
El grupo de obreros entrevistados tanto en los desarrollos urbanísticos como en las viviendas únicas sostuvieron que se vieron favorecidos por el aumento de las obras de la construcción, aumento no solo atribuido por ellos al Pro.Cre.Ar, sino también a la construcción de edificios, rutas o reparación de instituciones públicas (hospitales, escuelas, etc.), ejecución de pavimento, de alcantarillas, etc. en el período bajo análisis.

Con referencia específica al plan, la puesta en marcha denotó la intervención del estado regulando en parte el mercado laboral. Este mercado, ante la merma de puestos laborales opera como disciplinador de la fuerza de trabajo (Cortes y Marshall, 1992) llevando a los trabajadores a aceptar condiciones laborales endebles, por fuera de la seguridad social, como salida para mantenerse en esa intermitencia, trabajando de manera fugaz a contra-turno, para asegurarse un ingreso que puede ser semanal o quincenal aunque no esté registrado como trabajador.

\section{Los loteos del Pro.Cre.Ar. Conquista constreñida en zonas rururbanas del aglomerado Gran Paraná}

Además de la repercusión del Pro.Cre.Ar en la vida cotidiana de los adjudicatarios, el impacto llegó, como dijimos, a otros actores involucrados de manera directa (obreros, profesionales, técnicos, etc.) o indirecta (la propia dinámica de consumo a través de la ejecución de las obras). De esta forma, el Plan, aún con limitaciones, motorizó el mercado laboral e incentivó a otros sectores de la economía (electricidad, metalurgia, transporte, mobiliarios, etc.).

Otro de sus alcances se relaciona con la constitución de nuevas tramas urbanas en los loteos adquiridos por los adjudicatarios, muchos de ellos en los ejidos de ciudades pequeñas o intermedias, que hoy son denominados zonas rururbanas. Para captar estas nuevas tramas utilizamos la fotografía en el recorrido en campo, con observación directa, junto a la cartografía como herramienta anexa. Sumamos en el recorrido algunos testimonios recogidos en diálogos informales y luego guiábamos los ejes de las entrevistas con propietarios que estaban trabajando en sus construcciones.

Es sabido que hay una dinámica permanente en el territorio urbano de cualquier ciudad y que en esa metamorfosis operan las acciones espontáneas de la población, las políticas económicas subyacentes junto a otras políticas públicas y decisiones de organizaciones estatales o privadas en cada caso. Ello no obstante, encontramos formas de gobernanza gestadas según las oportunidades o restricciones del sector social al que se quiere llegar o sobre el cual se trata de intervenir.

Para develar el sentido del dinamismo de este plan de viviendas en las zonas aledañas a Paraná Capital, nos adentramos en las localidades de San Benito, Colonia Avellaneda y Oro Verde, situadas en el aglomerado Gran Paraná, desde el supuesto de que en estas tramas se conjugan representaciones de la vida cotidiana y del Estado construidas por 
los nuevos propietarios de las viviendas. Resulta oportuno en este particular el planteo de Daniela Soldano (2009:235) cuando relaciona los puntos de unión entre Estado y sociedad a partir de la implementación de una política social, en cuanto "es un excelente contexto para pensar los procesos de representación social en torno al fenómeno estatal, pero también es una escala a partir de la cual abordar las relaciones que los actores establecen con sus figuras o mediaciones".

La textura de los espacios estudiados da cuenta -por el tipo de viviendas, la mayoría siguiendo los prototipos previstos- de que este plan se orientó a atender los reclamos de los sectores medios de nuestra sociedad. Nos referimos a indicadores que lo evidencian como las formas de construir las casas en los loteos acorde a un tipo de desarrollo urbano, pero además, lo que se considera nivel cultural y estilo de vida se ve posibilitado por determinadas condiciones materiales. Estas conductas y valoraciones expresan las aspiraciones de familias de clase media y se trasladan a la trama urbana objetiva.

La distribución territorial pone en evidencia un uso racional y armónico de los lotes, lo cual le otorga un equilibrio al espacio: las viviendas van poblando las zonas rururbanas dentro del ejido del aglomerado. Esto es un rasgo diferenciador respecto a construcciones más pauperizadas donde prima la racionalidad de instalarse "donde y como se puede".

Las viviendas Pro.Cre.Ar en muchos casos tienen dos plantas, elementos de construcción y rasgos habitacionales que reflejan necesidades y aspiraciones de la clase media (construcciones de material, tanques de agua, calentadores solares, ventanas, persianas). Esto fue observado en el recorrido por los loteos y luego se constató en la propia fuente documental de la página del ANSES PROCREAR, que en uno de los apartados trata el tema de los loteos y expresa:

(...) se dispone de recursos públicos y se trabaja en forma articulada con provincias y municipios de todo el país, generando acciones coordinadas que permitan planificar y desarrollar ciudades inclusivas. Este trabajo es posible gracias a un fuerte involucramiento de los gobiernos locales quienes ceden tierras fiscales en zonas urbanas para la generación de lotes con todos los servicios de infraestructura. (ANSES, 2013)

En las propuestas, por una parte se ponderaba la accesibilidad económica en la adquisición del lote y por otra la accesibilidad en cuanto a facilitar la comunicación y desplazamiento de las familias. 


\section{Los factores exógenos limitantes}

Así como hemos mostrado rasgos comunes, los recorridos de los adjudicatarios no han sido lineales, tanto en los años que lograron acceder al crédito, como posteriormente, al sortear las dificultades económicas que fueron surgiendo.

Este plan, en un primer momento, trataba de llegar a un amplio sector de la población, pero esto se fue desmarcando (años 2013/2015) por el contexto económico atravesado por múltiples factores o trabas, y fue dejando fuera a aquellos grupos que sufrían inestabilidad en el puesto de trabajo o no tenían capacidad de ahorro, problemas que se sumaban a las propias dificultades que acarrearon la inflación y el alza de precios.

En el caso de la inflación, los porcentajes anuales fueron marcando otra de las grandes limitantes en las proyecciones de los hogares, tanto al pensar en lograr el crédito como a la hora de decidir cómo ejecutar su vivienda. Esto se debió a los fuertes aumentos en el costo de vida de un año a otro, $\mathrm{y}$ al desfasaje en los ritmos de de precios con respecto a salarios.

En el año 2012 la inflación cerró con un 25,9 \%.7 Al año siguiente creció aún más (28,3 \%), dando un salto de más de 10 puntos (38,5\% en 2014), hasta alcanzar casi un $27 \%$ en el 2015. Por otra parte operó la suba de precios de los materiales que componen el Índice de la construcción. Ambos factores fueron permeando los proyectos de diferentes grupos sociales que dejaron de acceder a esta posibilidad y esta política quedó más enfocada en los grupos o sectores medios.

En síntesis, este plan apuntó a satisfacer la demanda de los sectores medios a quienes les venía siendo difícil acceder a la vivienda propia. Pero en muchos casos, cuando el sueño estaba por concretarse, se frustró. El aumento de los valores de los terrenos derivó en la propuesta (alentada por las voces de los adjudicatarios) de asentar las viviendas en tierras fiscales. Al momento de negociar, una de las demandas fue que los lotes contasen con todos los servicios básicos (agua, luz, cloacas) exigencia inherente a los estilos de vida y necesidades que este sector social prioriza. La demanda se concatena con las expectativas del sector social al que estuvo direccionado el plan, pues no solo deseaban la vivienda propia, sino que demandaban ser propietarios de los terrenos, y esta política atendió también esta cuestión.

\section{Las tierras fiscales y las voces de los adjudicatarios de sectores medios}

Identificamos a los sectores sociales medios o clase media aludiendo a las condiciones y manifestaciones que los caracterizan en su modo de vivir, sus intereses y su cultura. ${ }^{8}$ Marx (1985) identificó a este grupo como la pequeña burguesía -por ser un sector intermedio entre los obreros y los burgueses- que, en la esfera de la producción, incluyen la distribución, la circulación y el consumo al que aspiran y las exigencias que ellos 
ponen en juego. En este caso, lo equiparamos en relación a las condiciones exigidas para adquirir los terrenos y su ubicación territorial.

En cada provincia y en cada localidad, el juego de tensiones y la necesidad de visibilizar la lucha por los terrenos en tierras fiscales, se presentaron con heterogeneidades, según las negociaciones logradas. En lo que atañe a las aspiraciones, el perfil de los adjudicatarios presentaba cierta homogeneidad. No así en lo que refiere a las formas de adquirir los terrenos. Es por ello que muchos propiciaron negociar en conjunto o solicitar la intermediación de las autoridades municipales.

Las relaciones Estado-sociedad se gestaron procesualmente en el marco de esta política pública. Los adjudicatarios muchas veces, después de manifestarse públicamente utilizando los medios de comunicación para dar visibilidad a sus reclamos, lograron el lazo entre su representación y la legitimación del Estado a través del contacto más directo: los representantes de los municipios. Soldano (2009) expresa que el momento de encuentro entre ciudadanos y Estado encarna empíricamente el momento (o el soporte) de la legitimación y de sus crisis.

En estas luchas y tensiones, algunos adjudicatarios pudieron mantenerse en su ciudad de residencia -Paraná capital-; otros grupos obligados por las limitaciones económicas, optaron por localidades aledañas a la misma que configuran el aglomerado Gran Paraná. Los adjudicatarios de este grupo social valoraron los terrenos pues contaban con elementos que los identifican en lo que se podría denominar su "cultura material” (Rosati y Donaire, 2012) como es el asfalto o la broza, las alcantarillas, el alumbrado público, las cloacas. Esto es fácilmente apreciable en la cartografia y el soporte visual. En otro plano, aunque en la misma línea de análisis, se visualizaron elementos que expresaron la regeneración de algunos vínculos debilitados en la descripta fragmentación. Nos referimos a que los propios adjudicatarios generaron estrategias de organización y reconocimiento grupal, no sólo con planteos ante el gobierno local, particularmente en las ciudades de Paraná y San Benito, sino además como modo de identificarse grupalmente desde las necesidades comunes.

Muchos adjudicatarios de los loteos expresaron que la organización espontánea les permitió accionar como "grupo de presión" no solo para lograr una mejor ubicación, sino, una vez instalados en el lugar y a medida que finalizaban las obras, para que se responda a otras demandas ajustadas a lo cotidiano, por ejemplo solicitar extensiones de servicios -transporte interurbano, entre otros-. Operó en los grupos la intercomunicación a través de redes sociales -Facebook-, que posiblemente hoy sea sustituida o complementada con los grupos de whatsapp. Esta modalidad también les permitió actuar desde un colectivo y cuidarse entre ellos a medida que las obras avanzaban para evitar la intrusión a terrenos y viviendas. Los grupos se conformaron apenas realizadas las primeras reuniones informativas acerca de la presentación de los proyectos y la disponibilidad de terrenos, 
ubicaciones y costos, ya que como hemos señalado, sobre todo en las grandes ciudades, se produjo un incremento significativo en los avalúos de terrenos factibles de destinarse al programa. Esto último, no obstante, activó la dinámica de crecimiento y desarrollo local de las ciudades pequeñas, circundantes a las capitales provinciales.

A continuación se hace referencia de manera específica a la realidad de lo acontecido en el Gran Paraná.

\section{Los nuevos espacios rururbanos a través del Pro.Cre.Ar en el aglomerado Gran Paraná (San Benito, Oro Verde)}

Al referirnos al Gran Paraná, lo hacemos desde el concepto de aglomerado que presenta INDEC, ${ }^{9}$ a lo que se agrega que en acuerdo entre diferentes municipios a partir del año 2016 por ordenanza municipal, este mismo espacio fue denominado Área Metropolitana de la provincia de Entre Ríos. ${ }^{10}$ Paraná es la ciudad capital, administrativa por excelencia y está ubicada a la margen este del Rio Paraná, con una población con más de 240.000 habitantes, cercana a las localidades menores en donde se han asentado varias de las construcciones Pro.Cre.Ar y que hoy, por el extendido de viviendas, ensanchan la mancha urbana.

Referimos a dos de las localidades de densidades menores que están ubicadas a muy pocos kilómetros de la capital (Paraná) de la provincia de Entre Ríos: San Benito, localidad centenaria que se encuentra a $12 \mathrm{~km}$ de la ciudad capital, es una mezcla de ciudad y zonas de extensiones de campos que llegan a 10.000 habitantes y sólo un arroyo las divide. Oro Verde, es una pequeña ciudad ubicada a $10 \mathrm{~km}$ de Paraná, tiene población urbana y rural y se la denomina localmente como "Ciudad Universitaria" porque en ella se encuentran las sedes de dos universidades públicas (la Universidad Nacional de Entre Ríos y la Universidad Autónoma de Entre Ríos) así como la estación experimental del INTA (Instituto Nacional de Tecnología Agropecuaria).

Con la expansión de las viviendas y por el propio pedido de la ciudadanía, narrado por los adjudicatarios, se fueron modificando y ampliando las urbanizaciones y esto llevó a extender el recorrido de las líneas interurbanas de colectivos, lo cual permitió una mejor circulación de la población, cambiaron los tiempos de espera y se ofreció una mejor inter-conectividad con la ciudad capital.

Las conversaciones con los adjudicatarios y el análisis de la documentación disponible (cartografia e imágenes fotográficas) permitieron constatar cuáles son las necesidades a satisfacer de los sectores medios que han accedido al crédito. Se aprecia a su vez que, tanto en la forma de construcción como en la ubicación, prevalecen en estas nuevas urbanizaciones las trazas de calles que van componiendo las manzanas, haciendo del espacio urbano un lugar ordenado, cuidado, propio de la cultura de los sectores medios y posibles de ser regulado por los municipios. 
Las viviendas presentan diferentes estados de avance, según el momento en que se accedió a los créditos y las oportunidades de cada grupo familiar. Cada uno de éstos le fue dando la impronta personal al desarrollo de la vivienda, aunque conservando en parte los prototipos del plan. Los entrevistados expresaron las urgencias, las resignaciones o los pluses que estuvieron presentes en los diseños sus casas. Muchas de las estructuras son sólidas y están ubicadas en espacios definidos y las calles presentan sus cordones, lo cual reafirma que serán grupos familiares de sectores medios quienes habitarán dichas construcciones. Signos de una cierta homogeneidad en el diseño y en las formas de respetar la traza urbana.

Los significados descriptivos "son productos culturales visibles, entes artificiales fabricados por el ser humano y no destinados exclusivamente a la comunicación visual -edificios, vehículos, armas, trajes o uniformes cuyo interés visual puede ser muy grande, pero cuya visibilidad no sustenta su única función-" (Gubern, 1987:151). Encontramos marcas (casas de dos plantas, tanques de agua revestidos, aleros de protección en las fachadas, etc.) que van haciendo visibles estilos de vida adecuados a los gustos de los sectores medios.

La organización espacial está diseñada con una perspectiva del espacio "racionalista y funcionalista" (Boito y Espoz, 2012:55). Hay una interacción entre las calles que marcan la recta regulando las cuadrículas de cada manzana. Esta organización podría caracterizarse como un esquema disciplinario (Le Corbusier, 1930) pues la recta permite imaginar dónde ubicar al hombre, "fácil de vigilar y de asear, para que fuera fácil de orientarse en ella, para que se la recorriera cómodamente". Dicho orden estético y externo es inherente al imaginario social del sector medio o medio alto de la sociedad y en la práctica dicho disciplinamiento se trasunta también en la edificación de medianeras o la división con alambres -a veces de púa- para mantener la seguridad.

Las medianeras de alambre, en casas de una sola planta -algunas de las cuales fueron las primeras en construirse- muestran cómo se va dando lugar a mantener la privacidad de los espacios propios. Se dejan de lado los espacios comunes que en un principio permitieron mayores lazos de solidaridad y comunicación entre vecinos. No obstante existen otras cuestiones comunes que los integraron o integrarán al momento de demandar servicios de comunicación, pavimentación, $u$ otras necesidades que fueron surgiendo. Se concentra así una fuerza colectiva en la petición, como estrategia para hacer sentir la voz de los sectores medios.

Se podría decir que las divisiones de los espacios o lotes son fronteras que dan cuerpo a la propiedad privada de cada familia. Así se suman señales identitarias de este sector social: dispositivos como la recta de las calles configurando las manzanas, las medianeras, los avances en recorridos de las líneas de transporte, el asfalto, son cuestiones no menores que los sectores medios rescatan, solicitan y valoran. A la importancia de llegar a la vivienda propia se agregan la ubicación del loteo, la accesibilidad, la comunicación, el tiempo de comunicación con la ciudad capital, como items prioritarios a la hora de definir y seleccionar dónde construir. 


\section{Las voces de los adjudicatarios}

En las entrevistas realizadas a los adjudicatarios del crédito, se encontró una valoración positiva en términos generales, pues lograrlo fue "como un empuje" que les permitió pasar de meros inquilinos a propietarios “...ya me había hecho la idea de que iba ser inquilino de por vida, esto me permitió tener mi propio hogar...”, “...fue un sueño que pude concretar...",“...llegué a la vivienda propia...".

Entendemos simbólicamente que hay un puente de unión entre el accionar del Estado y las condiciones de vida de un sector de la población, desde la experiencia de salir seleccionado, pasar y cumplimentar los requisitos del Banco, hasta el momento de recibir el crédito, trayectoria que va incidiendo en los relatos identitarios, conjugada a las expectativas que despierta iniciar la construcción. En un primer momento, los montos para el prototipo de vivienda facilitaban llegar a lo básico. Luego, comenzaron a ser percibidos como escasos, a medida que los costos aumentaban y el contexto económico daba cuenta de un avance inflacionario, mientras los montos otorgados se mantenían fijos. Así los actores recurrieron a otras alternativas acotando aspiraciones en cuanto al tipo de vivienda, fundamentalmente en los casos que dependían exclusivamente del crédito.

No obstante estos avatares, acceder a la casa propia provoca en las subjetividades de los adjudicatarios dimensiones incalculables: no es meramente la casa, significa en el imaginario la idea de progreso, pertenencia, ascenso social, bienestar, propio aporte dado por la modernización reflejado en una movilidad ascendente. Dicha meta estuvo a veces condicionada y restringida cuando el crédito no alcanzó para cubrir todo el proyecto. La situación socioeconómica de cada uno marcó posibilidades o restricciones, entrando a jugar otros componentes del capital social y económico: tener o no terreno, ingresos extras al momento del otorgamiento del crédito, ahorros, ayuda familiar, esfuerzo personal puesto en la construcción de la obra, u otros.

Desde un análisis estructural puede ubicarse a los adjudicatarios como provenientes de los sectores medios, según ya hemos señalado. Di Virgilio y Gil de Anso (2012) afirman que las estrategias más utilizadas para alcanzar una solución habitacional por parte de los sectores medios han estado asociadas a la percepción de herencias, la capacidad de ahorro y/o el acceso a financiación en bancos o empresas constructoras, y en menor medida a la autoconstrucción o la intervención de organismos públicos. Sostienen las autoras que la mayoría de estas estrategias denotan el apuntalamiento de las redes de parentesco, ya sea a través de los beneficios sucesorios, mediante la posibilidad de cohabitar hasta tanto se acumulen los ahorros suficientes para efectuar la compra, la cesión de tierras, entre otras. De este modo, las líneas de crédito del Pro.Cre.Ar se inscriben como estrategias en el sentido que le dieron las autoras, y según nuestra experiencia en terreno éstas han sido complementadas en muchos casos con los ahorros que tenían los beneficiarios y la ayuda familiar. 
Sin duda que el espíritu del Pro.Cre.Ar fue atender a una demanda social, pero en el trayecto se conjugaron variadas situaciones problemáticas y estrategias desarrolladas por los adjudicatarios para sortearlas. Así surgían, al momento de comenzar la obra, contradicciones, confusiones y puntos conflictivos, contexto en que el apuntalamiento a través de las redes de parentesco estuvo presente. Los adjudicatarios expresaron, entre los mayores problemas, el tiempo transcurrido entre la presentación de la carpeta, la aprobación del proyecto y la puesta en marcha concreta de la obra. La presentación implicaba la elaboración de los planos de la casa en conjunto con el presupuesto, detalle del crédito otorgado, y una vez aprobado el monto, éste era inamovible, transformándose en una barrera en un país cuya situación económica se desestabilizaba, reflejándose en aumentos continuos de precios de los productos de la construcción, del traslado de materiales, de la mano de obra, etc.

Las expresiones de estos conflictos fueron “(...) cuánto más se demore en la aprobación y en efectivizar el crédito, con un proceso inflacionario creciente y la especulación de los empresarios de la construcción, más perjudicado estoy “, “(...) no sé cuánto van a tardar en el banco en aprobar mi carpeta. Hace ya más de tres meses que la presenté, (...) todo sube y no sé para qué me va alcanzar".Vemos que la espera se vivió como incertidumbre caótica sobre la cual el adjudicatario no tenía posibilidades de intervenir. Se adiciona a esto que para acceder al crédito debían ser trabajadores registrados: fuerte restricción teniendo en cuenta que en el mercado laboral los jóvenes son uno de los grupos con mayores problemas para lograr empleo registrado, primando el trabajo no registrado (informal, "en negro”), por lo que algunas familias solicitantes recibieron montos menores.

En el plano de la construcción, a la hora de comenzar la obra los proyectos aprobados contaban con un desfase de 20 a 30 \% respecto del presupuesto inicial, por la actualización del valor de la mano de obra y fundamentalmente de los materiales. Los entrevistados recurrieron a otros capitales económicos, y cada uno a su manera fue cubriendo estos gastos al margen del monto del crédito hipotecario: "recurrí a los ahorros que tenía", "vendí el auto", "le pedimos ayuda a nuestros padres, no llegamos". Se observa entonces que las estrategias para sortear esta restricción fueron variadas: "sacar un nuevo crédito en un banco para poder ir completando las etapas y así seguir avanzando en la obra " "que me sigan acreditando las etapas restantes del crédito”. Otras estrategias fueron: dejar de alquilar y volver a casa de padres o suegros para ahorrar el alquiler y destinarlo a achicar la diferencia; suspender la contratación de mano de obra, “....me tuve que poner a pegar ladrillos y aprender a hacerlo, porque si no hacía esto, no me alcanzaba la plata, no iba a poder finalizar para habitarla..." o modificar el proyecto: "eliminé una de las habitaciones planificadas originariamente para hacerla más adelante". Los entrevistados valoraron también la ayuda familiar: “( ...) por suerte mis viejos me ayudan mes a mes con el avance de la obra y pago de la mano de obra, es la única manera de llegar”. 
En la dinámica del programa, la gestión política no estuvo ajena a las demandas y en la búsqueda de mantener la legitimación como política y menguar posibles conflictos públicos, se tomaron medidas como por ejemplo celebración acuerdo de precios entre el Estado local y los corralones frente al aumento del precio de los materiales de construcción. Al momento de preguntar a los entrevistados si en los corralones se encontraban las marcas y productos incluidos en el acuerdo, si había diferencia con otros productos o si existía un descuento por "ser del Pro.Cre.Ar", la respuesta fue desalentadora. Ninguno pudo comprar a través de los acuerdos de precios, como tampoco hubo descuento. Uno de ellos justificó diciendo: “...tal vez el acuerdo de precios es sólo para las ciudades grandes de Buenos Aires, Córdoba o Santa Fe, porque acá el único beneficio que encontré es que un corralón me fie $\$ 25.000$ en ladrillos...".

Esta situación, que afectó a todos los adjudicatarios, fue mucho más devastadora para aquellos que contaban con la línea "compra de terreno y construcción" que sólo financiaba $\$ 150.000$ para compra del terreno, mientras la especulación del mercado inmobiliario produjo un aumento sin precedentes en los costos de los lotes que, en menos de un año, pasaron de un promedio de $\$ 90.000$ a $\$ 200.000$ dependiendo de la zona. Vale recordar que varias inmobiliarias directamente se negaron a vender argumentando que esto implicaba blanquear el dinero de la venta y dejaron de ofrecer los terrenos para este plan.

Muchos adjudicatarios solucionaron comprando terrenos en localidades aledañas a la que residían. Otros insistieron en que el loteo fuese en su ciudad de residencia. Una de las entrevistadas manifestó "junto a seis mujeres luchamos un año hasta conseguir un lote que estuviera ubicado en la ciudad de Paraná. En un primer momento no se lograba respuesta por parte de las autoridades municipales hasta que después de muchas manifestaciones, cortes de calle y salir por los medios de comunicación, se logró instrumentar una mesa de trabajo para encontrar una salida y lograr la aprobación de un loteo." Es así como se reagruparon tanto de manera personal como a través de las redes sociales, para exigir en conjunto a los gobiernos municipal y provincial la liberación de tierras fiscales o la mediación para que propietarios de grandes terrenos lotearan y así poder conseguir terrenos a precios moderados.

No obstante estos conflictos, el Pro.Cre.Ar incentivó al empleo y la producción al no agotarse en la satisfacción individual de los adjudicatarios y tener un efecto redistributivo de derrame, pues incorporó la construcción o refacción de la vivienda manteniendo en parte el dinamismo económico del sector de la construcción y con ello, permitiendo que otros sectores productivos que nutren al mismo (carpintería, muebles, vidrios, etc.) siguieran activos. 


\section{Pro.Cre.Ar y los profesionales de la construcción}

No fue ajeno al análisis escuchar las voces de los profesionales, pues los planos de vivienda presentados por los adjudicatarios necesitaron ser avalados por ellos (arquitectos, ingenieros, maestros mayores de obra); por ende, estos constituyen otro grupo que es preciso implicar en el análisis de esta política pública.

El paso siguiente al sorteo era la presentación de los formularios al banco, documentación que incluía los planos de la casa con la ineludible certificación profesional. No obstante y por lo general estos profesionales se desligaban de la ejecución o dirección de la obra. En las entrevistas realizadas comentaban que desligarse no significó no seguirla, pues el Plan establece inspecciones de avances que los involucran, “(...) porque nosotros somos los responsables civiles de lo que pase después con esa construcción, nosotros somos los que firmamos el proyecto...”. Además aunque no ejecuten ni dirijan la obra, se mantiene una relación con los obreros que se ve claramente cuando los mismos profesionales recomiendan que se los contrate.

Un dato a destacar es que para la línea "compra de terreno y construcción" el proyecto era elegido entre los muchos prototipos que el programa proponía. En cambio, si se era propietario del terreno, era posible el diseño original de la propia casa. Al elegir un prototipo previamente disponible, el adjudicatario reducía muchos gastos, pero igualmente se requería la certificación de un profesional.

Se ponen en juego así cuestiones éticas que los profesionales expresan de esta forma: “(...) nosotros adecuamos el plano para facilitarle el otorgamiento, ese no es el problema, el problema es que nos encontramos con un dilema ético profesional por ser que esos planos no son nuestros, no los elaboramos de una idea sino que son copiados de la página, pero los firmamos igual...".

El profesional cumplía también un papel fundamental a la hora de readaptar el presupuesto original a los precios actualizados, reduciendo gastos, modificándolos, sin que esto repercutiera en la calidad final de la vivienda.

Sintetizando entonces la relación del Pro.Cre.Ar con el grupo profesional de la construcción, esta política provocó un aumento considerable en la demanda de servicios profesionales, sin que significara un aumento de profesionalización al estar los modelos de vivienda pre-establecido.Al requerir el plan el aval profesional del diseño de la vivienda, se legitimó la presencia del Estado resguardando la gestión habitacional eje e incentivando la prestación de servicios profesionales como garantía del proyecto. En este sentido ampliamos la mirada del impacto del plan, al constatar que, además de llegar a los adjudicatarios, a los obreros y a otros sectores productores de bienes para la construcción, también impactó positivamente en el grupo profesional. 


\section{A modo de cierre}

Esta política pública considerada activa evidenció dinamismo así como logró mejorar la calidad de vida de muchos adjudicatarios, cumpliendo con "un sueño, la casa propia", otorgando con ello un rasgo humanizador a la política con un sentido social, y dejando ver que la planificación y la ejecución de las políticas públicas repercuten directamente en la vida cotidiana.

La participación del Estado estuvo presente en la generación del Fondo Fiduciario Público y en el financiamiento que requirió la participación de la ANSES. Sin duda el Pro.Cre.Ar modificó e incorporó diferentes cuestiones, haciendo frente a un contexto con duras reglas del mercado inmobiliario que impactaban en aumentos excesivos en los precios de los terrenos. Esto se resolvió acordando con provincias y municipios para facilitar la compra de terrenos fiscales, potenciando desarrollos urbanísticos municipales.

Se evidencia así una intervención del Estado que legitima su accionar mediante esta política de vivienda, superadora de algunos manejos propios del clientelismo político, porque el sorteo por la lotería nacional fue una acción de transparencia en la adjudicación. La documentación requerida por el Pro.Cre.Ar exigía certificación profesional y mecanismos legales como la licitación, posibilitando el ejercicio profesional de muchos profesionales y técnicos. El manejo de tasas bajas para la devolución de los créditos otorgados da cuenta de la tutela que la política ejerce sobre la cuestión social pues permite una mayor participación e incorporación de la ciudadana.

El Pro.Cre.Ar fue una política pública que trató de apaciguar y disminuir las brechas del déficit habitacional, abriendo y evaluando el contexto social año a año y considerando las posibilidades de los sectores medios, cuyas marcas y texturas se aprecian en los tipos de vivienda construidos, donde prevalecen pautas, estilos y necesidades de dicho sector social, que demandó la concreción de esta política acorde a lo que considera valioso en el tema vivienda.

Algunos adjudicatarios de sectores medios llevaron adelante reclamos grupales que mostraron marcas identitarias de su cultura material, y estos reclamos lograron dinamizar la política y el accionar de los municipios menores, en un marco donde las tensiones estuvieron presentes en la relación entre estado y ciudadanía, en la búsqueda de respuestas a demandas concretas.

El Pro.Crear.Ar se enmarcó en una política contra-cíclica, proactiva, y por ende, inclusiva al tratar de dar respuesta a la necesidad de la vivienda propia, sobre todo por el momento económico que se atravesaba en el país. Como política pública impulsada en un momento de reclamos y en una meseta en el crecimiento económico, enfatizó valores relacionados con la equidad y la inclusión al posibilitar el acceso de muchas familias a la vivienda propia, bien articulador de la vida cotidiana. Esto permite afirmar que tuvo en 
cuenta no solo la demanda, sino la subjetividad de los adjudicatarios y aportó a mejorar las condiciones de vida de muchos de los que accedieron al crédito.

El impacto social se percibió también en el plano de la economía, puntualmente en la producción de bienes para la construcción y en la prestación de servicios profesionales. En el mercado laboral, aportó a menguar la desocupación en el sector de la construcción y dio empuje a desarrollos urbanísticos. El lado negativo de la cuestión es que muchos de los puestos de trabajo, desempeñados mayormente por jóvenes, encuadran en lo que se denomina trabajo precarizado o no registrado.

La concreción de las viviendas a través del plan, aportó a menguar el déficit habitacional, pero no podemos decir que haya revertido el tema estructural de la vivienda que reclaman los sectores medios. 
${ }^{1}$ Las zonas rururbanas son espacios territoriales mixtos donde se combinan áreas de características rurales con otras propiamente urbanas. Los menores costes de emplazamiento y su mayor flexibilidad favorecen esta tendencia. ${ }^{2}$ Las fotografias se pueden solicitar a los correos electrónicos de las autoras.

${ }^{3}$ Otros de los planes más importantes son el Programa Federal de Construcción deViviendas con más de 166000 viviendas, el Fondo Nacional de laVivienda con más de 160000 y el Programa Federal MejorVivir con más de 75000. ${ }^{4}$ La crisis financiera internacional del 2008 se desató debido al colapso de la burbuja inmobiliaria en Estados Unidos, es la llamada crisis de las hipotecas subprime, luego desató otras crisis a nivel internacional.

${ }^{5}$ El Fondo Fiduciario creado “...emite deuda por oferta pública, calificada, por cotización en el MERVAL, con garantía del Estado Nacional, y tendrá una duración de 30 años.” Que a su vez, "el ANSES invierte a través del Fondo de Garantía de Sustentabilidad (FGS) en el Fondo Fiduciario de acuerdo a criterios de rentabilidad y seguridad adecuados durante los primeros 5 años. Además, cualquier inversor privado podrá invertir, dado que se trata de una oferta pública." (Página de ANSES, Financiamiento).

${ }^{6}$ El Desarrollo es una obra para 600 unidades habitacionales, con espacio para recreación y cuidado del medio ambiente, que se integrará con distintos proyectos de planificación, que actualmente se está terminando un nuevo Hospital, y fue aprobada la realización del Campus Universitario de la Universidad Autónoma de Entre Ríos, emplazado en la zona sur de la ciudad capital. Si bien, aún no se han realizado los sorteos de los distintos tipos de departamentos, se estima que beneficiará a unos 2400 paranaense.

${ }^{7}$ Debido a la situación institucional del INDEC en ese año, las cifras son estimaciones de consultoras privadas. ${ }^{8}$ En el sentido que le asigna Gino Germani: conjunto de individuos que tienen ciertos elementos comunes que se manifiestan concretamente en la manera de pensar y de obrar (Germani 1987).

${ }^{9}$ Los aglomerados reúnen dos o más componentes que pueden ser localidades, barrios u otro tipo de agrupamiento poblacional acorde a cada caso en particular. La diferencia de los aglomerados respecto de las demás localidades compuestas radica en que los primeros poseen una extensión y población de mayor importancia que llega a más 100.000 habitantes (INDEC).

${ }^{10}$ Área Metropolitana de la provincia, denominada Gran Paraná, que incluye a los municipios de Paraná, Oro Verde, San Benito y Colonia Avellaneda. 


\section{Referencias bibliográficas}

ANSES (varios años) Página Web http://procrear.anses.gob.ar/lote-servicio consultada el 12 de febrero de 2017.

Alonso, Guillermo y Valeria Di Costa (2013) "Más allá del principio contributivo: cambios y continuidades en la Política Social Argentina, 2003-2011". Estudios Sociológicos XXXVII (97) 31-62. Disponible en http://www.unsam.edu.ar/escuelas/ politica/documentos/Documento\%20N2_4.pdf. Fecha de acceso: 12/11/2016.

Boito, María Eugenia, Sorribas, Patricia Mariel y Espoz, María Belén (2012) Pensar los des-bordes mediáticos del conflicto: las ciudades-barrios como síntoma de la actual tendencia urbana de socio-segregación CIECS/ CONICET-UNC. Unidad Ejecutora del CONICET. Universidad Nacional de Córdoba, Colección Acción Social. Córdoba.

Castel, Robert (1997) La metamorfosis de la cuestión social: Una crónica del salariado. Buenos Aires, Paidós.

Cardarelli, Graciela y Mónica Rosenfeld (2001) Tutelados y asistidos. Programas sociales, políticas públicas y subjetividad. Buenos Aires: Paidos.

Cortés, Rosalía y Adriana Marshall (1993) "La política social y la regulación de la fuerza de trabajo" Cuadernos Médico - Sociales No 65-66. CESS, Rosario.

Crecimiento: la decepción de 2011/2015 disponible en http://www.tiempodeeconomia.com/2015/06/crecimiento-la-decepcion-de-20112015/http:// fedi.org.ar/ investigación-inmobiliaria/recuperado el 14/04/2016.

Denzin, Norman K. e Yvona Lincoln (2007) Manual de investigación cualitativa Volumen III. Buenos Aires: Gedisa.

Di Virgilio, María Mercedes y María Laura Gil y de Anso (2012) "Estrategias habitaciones de familias de sectores populares medios residentes en el área metropolitana de Buenos Aires (Argentina)" Revista de Estudios Sociales 44:158-170. Descargado de http://www.scielo.org.co/pdf/res/n44/n44a15.pdf. Consulta 15 de Febrero de 2017.

D’Amico, María Victoria (2013) "La política social en debate. Desigualdades, intervención estatal e inclusión social en la Argentina democrática" Cuestiones de Sociología 9:231-234. http://www.cuestionessociologia.fahce.unlp.edu.ar/.

FEDI, Fundación de Estudios para Desarrollo Inmobiliarios (2015) Informe sectorial de la Cámara Inmobiliaria Argentina. Departamento de Investigaciones de la FEDI. Buenos Aires. 
Germani, Gino (1987) Estructura Social de laArgentina. Buenos Aires:Editorial Solar-Hachette.

Gubern, Román (1987) La mirada opulenta. Barcelona: Editorial Gustavo Gilli.

INDEC, Instituto Nacional de Estadística y Censos (2012). Censo Nacional de Población, Hogares y Viviendas 2010. Censo del Bicentenario. Resultados definitivos, Tomo 1.Serie B N ${ }^{\circ}$ 2. Buenos Aires.

Jiménez Rosano, M. C. (2005) El ensayo fotográfico como Diseño de Información. El uso de la fotografía en la investigación exploratoria de un fenómeno social. Tesis Licenciatura. Diseño de Información de la Escuela de Artes y Humanidades, Universidad de las Américas Puebla. Descargado de ehttp://catarina.udlap.mx/u_dl_a/tales/documentos/ldf/jimenez_r_mc/capitulo_3.html\#.Consulta:12 de agosto de 2017

Le Corbusier, Charles Edouard (1962) El Camino de los Asnos. El Camino de los Hombres. Texto publicado en el libro La Ciudad del Futuro / Buenos Aires: Ed. Infinito (Bib. de Planeamiento y Vivienda,Vol.6) disponible en http://www.revistacontratiempo.com.ar/lecorbusier1.htm Consulta 16 de febrero de 2017.

Marx, Carlos (1985) El 18 brumario de Luis Bonaparte. Barcelona: Editorial Planeta Agostini.

Mingo, Graciela, César Sione et al (2013) El Sector de la Construcción en Paraná: Su dinámica acorde a las Políticas y el Contexto de Crisis Internacional. Periodo2008-2010.Disponible en https:// www.aset.org.ar/congresos/10/ponencias/p1_Mingo.pdf. Consultado el 30 de marzo de 2017.

Offe, Claus (1994) Contradicciones del Estado de Bienestar. Madrid: Editorial Alianza.

Rosati, Germán y Donaire, Ricardo (2012) "Sobre los supuestos de la "homogeneidad” en el análisis de la estructura social” Entramados y Perspectivas. Revista de la carrera de sociología 2 (2) 71-98.

Soldano, Daniela y Luciano Andrenacci (2006) “Aproximación a las teorías de la política social en el caso argentino”. En Andrenacci, L. (comp.) Problemas de Política Social en la Argentina contemporánea Buenos Aires: UNGS/Editorial Prometeo, pp. 17-79.

Soldano, Daniela (2009) El Estado en la vida cotidiana. Algunos desafíos conceptuales y metodológicos de la investigación sobre política y biografía. En Sabrina Frederic y Germán Soprano (comps.) Política y variaciones de escalas en el análisis de la argentina. Buenos Aires: UNGS/Prometeo, págs. 235-254

\section{Cómo citar este artículo:}

Mingo, Graciela y Elisa Sarrot (2018) “Estado y actores sociales en la política pública. El caso del Pro.Cre.Ar en la provincia de Entre Ríos (2012-2015)”. Revista Perspectivas de Políticas Públicas, vol. 8 No15:207-231 